CEMENT and CONCRETE RESEARCH. Vo1. 13, pp. 869-876, 1983. Printed in the USA. 0008-8846/83 $\$ 3.00+00$. Copyright (c) 1983 Pergamon Press, Ltd.

\title{
STATISTICAL LINEAR REGRESSION ANALYSIS OF PREDICTION MODELS FOR CREEP AND SHRINKAGE
}

\author{
Zdeněk $P$. Bažant and Steven Zebich \\ Center for Concrete and Geomaterials \\ The Technological Institute \\ Northwestern University \\ Evanston, I11Inois 60201, U.S.A.
}

\author{
(Communicated by F.H. Wittmann) \\ (Received May 3; in final form June 22, 1983)
}

\section{ABSTRACT}

Several models for the prediction of creep and shrinkage of concrete are compared statistically with test data available in the literature. The models are algebraically transformed into a linearized form and statistical regression is then carried out. Although the BP Model performs distinctly better than the ACI and CEB-FIP Models, the scatter is large for all models, due to the difficulty in predicting material parameter values without any tests of the given concrete.

\section{Introduction}

Practical probabilistic analysis of concrete creep and shrinkage has recently been rendered meaningful by extraction of an extensive body of statistical information from the 1iterature; see Ref. 1 and 2, in which test data for 80 different concretes from various laboratories throughout the world, consisting of over 800 experimental curves and over 10,000 data points, have been analyzed statistically. It has been shown that, if no measurements for a given concrete are made, the uncertainty of its creep and shrinkage prediction on the basis of the chosen concrete mix parameters and the chosen design strength is enormous (and is much larger than for strength). From all the data considered in Ref. 1, it was determined that, on the whole, the prediction errors that are exceeded with a $10 \%$ probability ( $90 \%$ confidence 1 imits) are, for the best known practical prediction models, as follows: BP Model [1]: $\omega_{90}=31 \% ;$ ACI - 1971 Model [3]: $\omega_{90}=63 \%$; CEB-FIP - 1978 Mode1 [4]: $\omega_{90}=70 \%$.

The first of these models is to a greater extent than the others based on physical considerations and is applicable over a much wider range of conditions. However, it is relatively complicated. The second model is much simpler, and still represents probably the optimum prediction method at its degree of simplicity. The desire for simplicity should not be exaggerated, however. Since the errors in the prediction of creep effects in structures are caused more by errors in prediction of creep properties than by simplifications of structural analysis, the designer should spend more time on careful 
determination of material characteristics than he does on structural creep analysis per se.

The purpose of this brief study is to report the results of some further statistical analysis of the creep and shrinkage data available in the literature. In addition to simple statistics of the population of errors obtained in Ref. 1 and 2, statistical linear regression is applied here. The advantage of the linear regression approach is that it allows for the variation of the standard deviation or coefficient of variation with time. In particular, it yields, as it should, a larger uncertainty for long-time extrapolations than it does for predictions at times corresponding to the centroid of available data.

\section{Processing of Data}

As for the measurement error, this error represents an uncertainty that is not "felt" by the structure, but only by the observer; therefore, this error should not be included in the creep and shrinkage prediction models for design, and should be eliminated from the measured data.

Before undertaking statistical analysis, test data reported in the literature have to be processed first, for two reasons (1) The reading times have not been selected in a manner which would assure an unbiased weighting of successive time intervals; and (2) the data contain random fluctuations due to measurement error.

To eliminate the aforementioned effects (1) and (2), it is convenient and perhaps sufficient to smooth the reported data points by hand, and then to take the data points for statistical analysis as the ordinates of the handsmoothed curves at intervals spaced regularly in the logarithm of creep duration or shrinkage duration, normally two points per decade in the logarithmic scale. This approach to the processing of raw data from the literature has been followed in Refs. 1 and 2 as well as the present study. A fully computerized data bank, involving essentially all the test data analyzed in Refs. 1 and 2, has been developed at Northwestern University.

In this data bank, the data points are organized in subscripted arrays, in which the first subscript refers to the number of the data point on the creep curve, the second subscript to the number of the creep curve within a certain data set, and the third subscript to the number of the data set. One array gives the creep durations for all data points and one array gives the strain values. Another array gives the ages at loading for all curves. A further integer array defines the number of all data points on each creep curve, the number of all curves in a given data set, and the number of all data sets in the data bank. Two data banks were generated; one for the points taken from the hand-smoothed data curves at properly spaced time interva1s, and one for the unprocessed original data as reported. The data bank tremendously reduces the labor in extracting various statistics.

The analysis in Ref. 1 and 2 established the statistics (principally, the coefficient of variation) of the collection of deviations of handsmoothed data from the prediction formulas for the compliance function and for the shrinkage strain. Statistically a more fundamental approach would be to analyze the variability of the parameters of the prediction formulas and use it to determine the variation of various characteristics, such as the coefficient of variation, with the independent variables such as the load duration or the age at loading. Such an approach is, however, difficult because of the nonlinearity of the prediction formulas for the compliance function and the shrinkage strain. 


\section{Linear Regression}

To facilitate statistical regression, one needs to transform the prediction formulas into a linear form to which the standard linear regression analysis could be applied. In a linear form, a prediction formula for creep and shrinkage may be written as:

$$
y=a+b x+e
$$

in which $\mathrm{x}$ and $\mathrm{y}$ are the transformed independent and dependent variables, $\mathrm{b}$ is the slope, a is the y-intercept, and $e$ is the error. The transformation is such that for a perfect model $b=1$ and $a=0$.

Consider now basic creep, i.e., the creep at constant water content. The double power law for fasic creep $[1,5]$ may be transformed to the following form:

$$
\begin{aligned}
& y=E_{0} J\left(t, t^{\prime}\right)-1 \quad \text { (= creep coefficient) } \\
& x=\phi_{1}\left(t^{,-m}+\alpha\right)\left(t-t^{\prime}\right)^{n}
\end{aligned}
$$

in which $J\left(t, t^{\prime}\right)=$ creep compliance (also called the creep function), representing the strain at age $t$ caused in concrete by a constant uniaxial unit stress acting since age $t^{\prime} ; \mathrm{E}_{0}, \phi_{1}, \mathrm{n}, \mathrm{m}$, and $\alpha=$ material parameters defined in Ref. 1 or 10. The most important test data on basic creep, including those of L'Hermite et al., Hanson and Harboe (Shasta Dam, Ross Dam, and Canyon Ferry Dam), Browne et al. (Wylfa vesse1), Pirtz et al. (Dworshak Dam), and Rostasy et al. (for references, see Ref. 1), have been subjected to regression analysis according to Eqs. 1-2. The resulting regression line (Eq. 1), as well as the $90 \%$ confidence 1 imit for the mean prediction and for the individual data points, are shown in Fig. 1a. The corresponding statistics are listed in Table 1 , in which $\bar{x}, \bar{y}$ is the centroid of all data points, $s, s_{y}$ are the standard deviations of the data points, $s_{b}$ is the standard deviation of slope $b, s_{y} \mid x$ is the standard deviation of the data points from the regression 1 ine, and $r$ is the correlation coefficient. One is

There are other ways to transform the double power law to a linear form.

$$
y=\log \left(\frac{J\left(t, t^{\prime}\right) E_{0}-1}{\phi_{1}\left(t^{r-m}+\alpha\right)}\right), \quad x=n \log \left(t-t^{\prime}\right)
$$

and the regression analysis of the same data based on this equation is shown in Fig $1 \mathrm{~b}$. The statistics are again given in Table 1.

The ACI Model $[3,5]$ can be transformed to a linear form as follows

$$
y=E\left(t^{\prime}\right) J\left(t, t^{\prime}\right)-1, \quad x=C_{u}\left[1+10\left(t-t^{\prime}\right)^{-0.6}\right]^{-1}
$$

in which $E\left(t^{\prime}\right)$ is the conventional elastic modulus at age $t^{\prime}$, and $C_{u}$ is a material parameter calculated as a product of six other empirical parameters [3]. Regression analysis of the same test data according to this equation is shown in Fig. Ic, and the statistics are again summarized in Table 1. follows

The CEB Model $[4,5]$ can be transformed to a linear form (Eq. 1) as

$y=E_{28} J\left(t, t^{\prime}\right)-\frac{E_{28}}{E_{c}\left(t^{\prime}\right)}-\beta_{a}\left(t^{\prime}\right), x=\phi_{d^{\prime}} \beta_{d}\left(t, t^{\prime}\right)+\phi_{f}\left[\beta_{f}(t)-\beta_{f}\left(t^{\prime}\right)\right]$ 

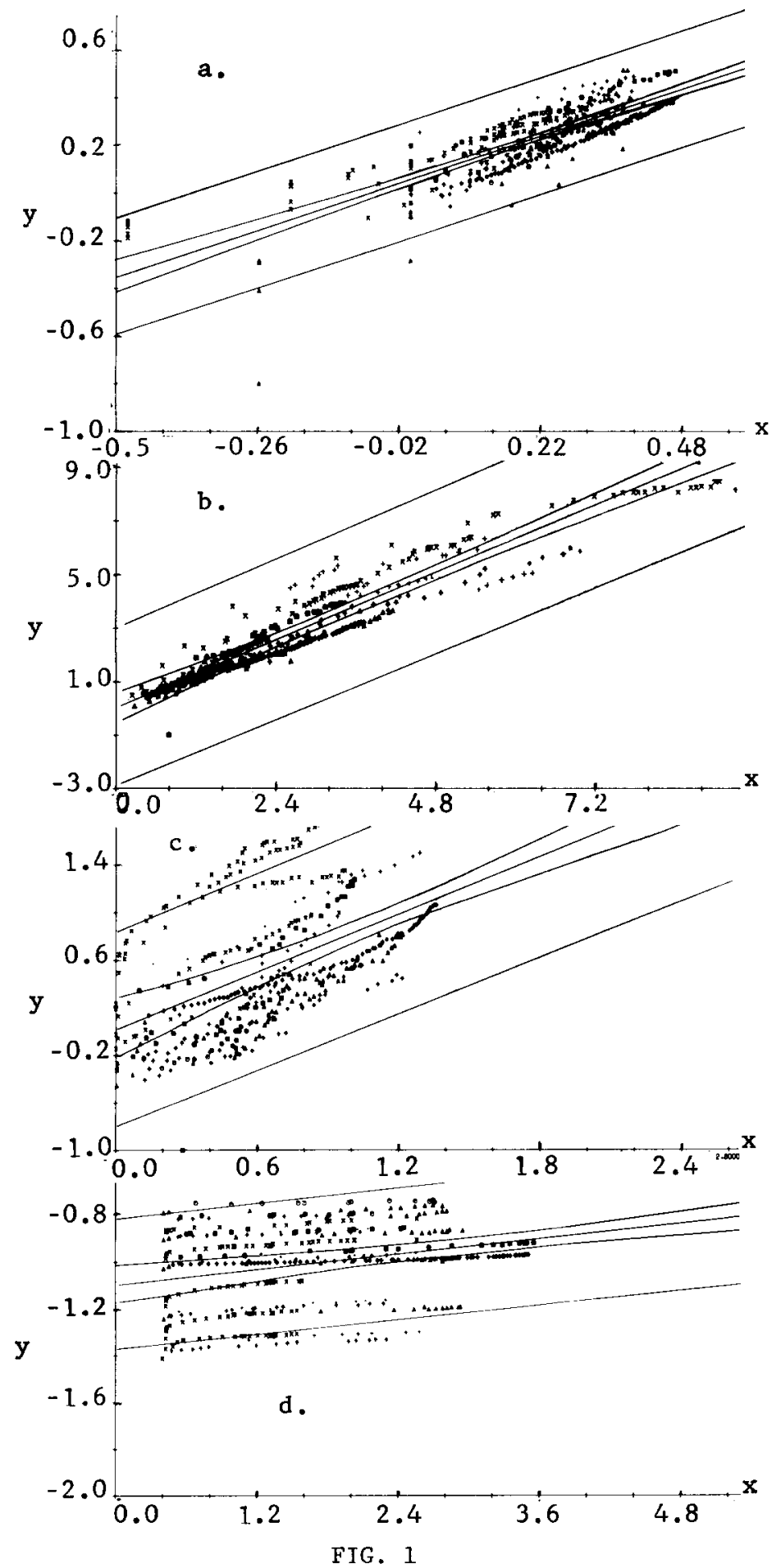

Regression of Basic Creep Data for the BP Model

( $a, b)$, the ACI Model (c), and the CEB-FIP Model (d). 
in which $E_{28}, E_{c}, \beta_{a}, \phi_{d}, \beta_{d}, \phi_{f}$, and $\beta_{f}$ are material parameters and functions defined in Ref. 6 graphically, by means of sixteen curves. The results of the regression analysis for the same test data as before are shown for this model in Fig. 1d, and the corresponding statistics are listed in Table 1.

The BP Model for shinkage can be brought to a linear form in various ways, and one is

$$
\left.y=\log \left[\left(\frac{\varepsilon_{\infty}}{\varepsilon_{\text {sh }}}\right)^{2}-1\right], \quad x=\log \frac{\tau}{\hat{t}} \quad \hat{(t}=t-t_{0}\right)
$$

For the ACI Model, linerization may be achieved as follows

$$
y=\log \left(\frac{0.0078}{\varepsilon_{s h}}-1\right), \quad x=\log 55-\log \hat{t}
$$

and for the CEB Model as follows

$$
y=\log \left(\frac{\varepsilon_{s h}}{\varepsilon_{s o}}\right), \quad x=\log \left[\beta_{s}(t)-\beta_{s}\left(t_{0}\right)\right]
$$

In these equations, $\varepsilon_{\text {sh }}$ is the shrinkage strain, $\hat{t}$ is the duration of drying, ${ }^{t_{0}}$ is the age at the start of drying, $\tau_{s h}$ is the shrinkage-square half-time, proportional to the effective thickness squared, and $\varepsilon_{\infty}, \tau_{s h}$, $\varepsilon_{\text {so }}$, and $\beta_{s}$ are material parameters and functions defined in Refs. 1, 2, 4, and 6. The most important shrinkage data from the literature, involving those of Hansen and Mattock, L'Hermite et al., Kesler et al., Troxel et a1., and Keeton (for references cf. Ref. 1), have been used in regression analysis. The results for Eqs. 6, 7, and 8 are shown in Fig. 2a, b, c, respectively. The corresponding statistics are listed in Table 1.

A similar regression analysis could be carried out for creep during drying In this case the linear regression plots are, however, less relevant, because creep at drying is a sum of a basic creep term and a drying creep term, both of which cannot be simultaneously varied in the regression plot. One of these terms must be fixed, and linear regression may then be carried out for the other term. For this reason, linear regression analysis of creep at drying for the BP Model would not be very informative.

The regression plots in Figs. 1 and 2 visually demonstrate the degree of agreement of the three models with the test data. Quantitatively, the degree of agreement is reflected best by the correlation coefficient $r$ in Table 1 ; for perfect correlation $r=1$, and the more $r$ differs from 1 , the poorer is the representation of test data. From these comparisons it appears, similarly to the conclusions of Ref. 1 and 2, that the BP Model agrees with test data better than the other models.

The linear regression analyses in transformed variables must, however, be regarded with reservation since the transformation of variables generally introduce some bias, due to a change in weighting of various time intervals as well as possible superimposition of a deterministic dependence. Therefore, in spite of certain advantages already mentioned, the comparisons in terms of the regression in Figs. 1 and 2 should be considered secondary to the comparisons in terms of the deviations of the compliance values or the shrinkage values $[1,2]$. 


\section{Z.P. Bažant and S. Zebich}
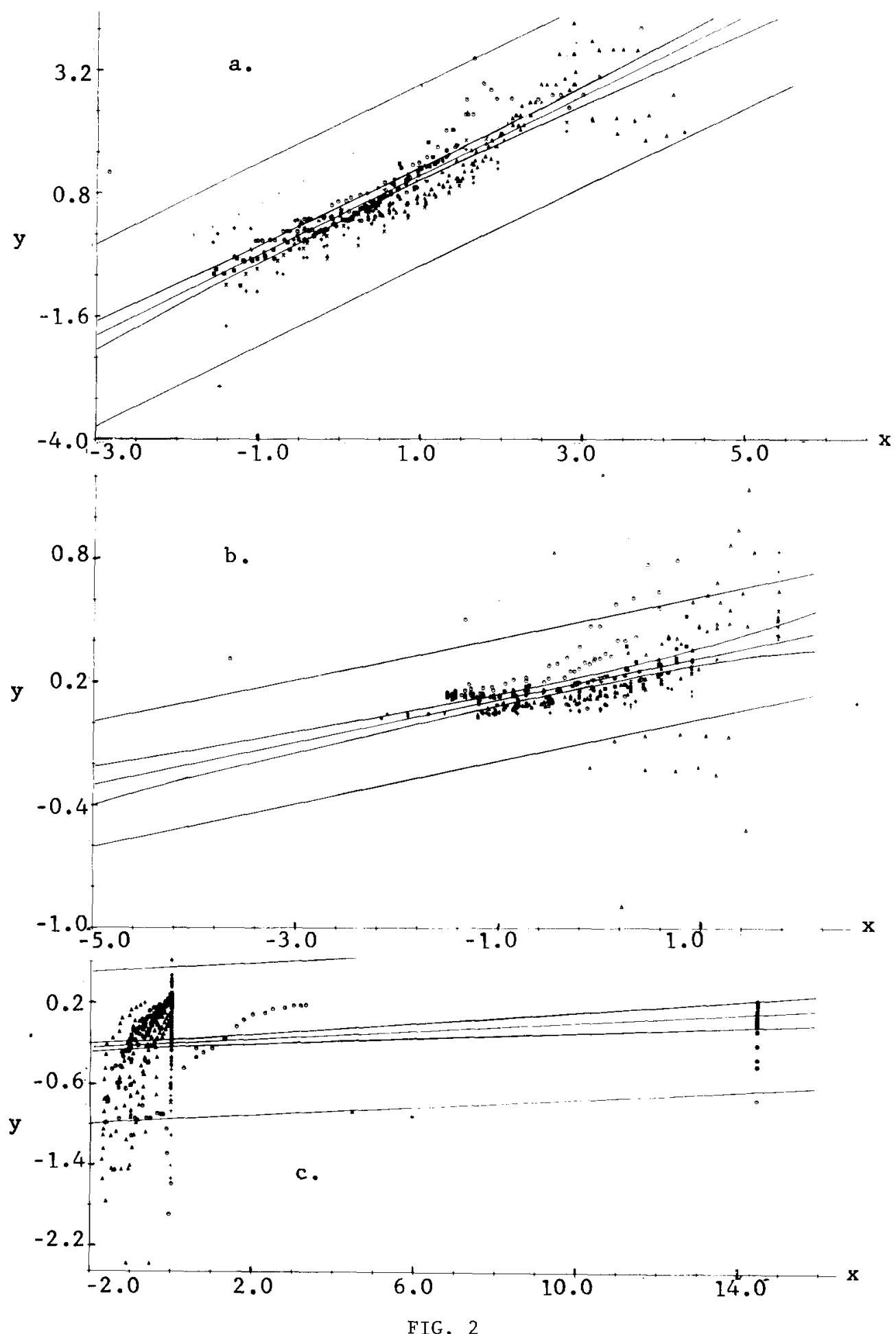

FIG. 2

Kegression of Shrinkage Data for the BP Model (a), the ACI Model (b), and the CEB-FIP Model (c). 
CREEP, SHRINKAGE, MODELS, STATISTICAL REGRESSION

TABLE 1

Linear Regression Statistics of Test Data

\begin{tabular}{|c|c|c|c|c|c|c|c|c|c|}
\hline Statistics & $\overline{\mathrm{x}}$ & $\bar{y}$ & $s_{x}$ & $s_{y}$ & $a$ & $\mathrm{~b}$ & $s_{b}$ & ${ }^{s} y \mid x$ & $r$ \\
\hline $\begin{array}{l}\text { a) Basic Creep } \\
\text { BP }\end{array}$ & & & & & & & & & \\
\hline $\begin{array}{l}\text { Eq. 2, Fig. la } \\
\text { Eq. 3, Fig. 1b } \\
\text { ACI }\end{array}$ & $\begin{array}{l}0.495 \\
2.559\end{array}$ & $\begin{array}{l}0.464 \\
2.739\end{array}$ & $\begin{array}{l}0.351 \\
1.713\end{array}$ & $\begin{array}{l}0.306 \\
1.916\end{array}$ & $\begin{array}{l}0.019 \\
0.180\end{array}$ & $\begin{array}{l}0.999 \\
1.062\end{array}$ & $\begin{array}{l}0.005 \\
0.003\end{array}$ & $\begin{array}{l}0.304 \\
1.92\end{array}$ & $\begin{array}{l}0.820 \\
0.933\end{array}$ \\
\hline $\begin{array}{l}\mathrm{Eq} \cdot 4, \mathrm{Fig} \cdot \mathrm{IC} \\
\mathrm{CEB}\end{array}$ & 0.630 & 0.520 & 0.335 & 0.521 & -0.109 & 0.822 & 0.004 & 0.522 & 0.521 \\
\hline Eq. 5, Fig. 1d & 1.703 & -1.004 & 0.862 & 0.173 & -2.107 & -0.485 & 0.005 & 0.173 & 0.265 \\
\hline $\begin{array}{l}\text { b) Shrinkage } \\
\text { BP }\end{array}$ & & & & & & & & & \\
\hline $\begin{array}{l}\text { Eq. } 7, \text { Fig. } 2 a \\
\text { ACI }\end{array}$ & 1.423 & 1.484 & 2.855 & 1.912 & 0.240 & 0.899 & 0.004 & 1.915 & 0.870 \\
\hline $\begin{array}{l}\text { Eq. } 8, \text { Fig. } 2 \mathrm{c} \\
\text { CEB }\end{array}$ & -0.495 & 0.166 & 1.973 & 0.185 & 0.411 & 0.044 & 0.005 & 0.185 & 0.479 \\
\hline Eq. 9, Fig. 2c & -0.154 & -0.204 & 0.866 & 0.459 & -0.050 & 0.116 & 0.012 & 0.460 & 0.146 \\
\hline
\end{tabular}

Concluding Remarks

The reason for the error of all models for the prediction of creep and shrinkage is not a poor knowledge of the governing law but the difficulty of predicting the values of material parameters in the governing model. If a few short-time measurements are taken, creep prediction can be drastically improved [2]. Bayesian approach is effective for this purpose $[6,7]$.

\section{Acknowledgment}

Partial support under U. S. National Science Foundation Grant No. CEE8009050 deserves mention.

\section{References}

1. Bažant, Z. P., and Panula, L., "Practical Prediction of Time-Dependent Deformations of Concrete," Materials and Structures, Part I and II:

Vo1. 11, No. 65, 1978, pp. 307-328, Part III and IV: Vol. 11, No. 66, 1978, pp. 415-434. Parts V and VI: Vol. 12, No. 69, 1979.

2. Bažant, Z. P., and Panula, L., "Creep and Shrinkage Characterization for Prestressed Concrete Structures," J. of the Prestressed Concrete Institute, Vo1. 25, 1980, pp. 86-122.

3. ACI Committee 209/11 (chaired by D. E. Branson), "Prediction of Creep, Shrinkage and Temperature Effects on Concrete Structures," ACI-SP27, Designing for Effects of Creep, Shrinkage and Temperature, American Concrete Institute, Detroit, 1971, pp. 51-93, and revised version in ACI-SP-76, Detroit, 1982, "Designing for Creep and Shrinkage in Concrete Structures (A. Pauw Symp., held at ACI Convention, Houston, 1979). 
4. CEB-FIP Mode1 Code for Concrete Structures, Comité Eurointernational du Béton-Fédération Internationale de la Précontrainte, CEB Bulletin No. 124/125-E, Paris 1978.

5. Bažant, Z. P., "Mathematical Model for Creep and Shrinkage of Concrete," Chapter 7 in "Creep and Shrinkage in Concrete Structures," ed. by Z. P. Bazant and F. H. Wittmann, J. Wiley, London 1982, pp. 163-256.

6. Bažant, Z. P., "Probabilistic Approach in Prediction of Creep and Shrinkage Effects in Structures," Proc. 4th Intern. Conf. on Applications of Statistics and Probability in Soil and Structural Engineering, (ed. by G. Augusti), Florence, Italy, June 1983.

7. Bažant, Z. P., and Chern, J. C., "Bayesian Statistical Prediction of Concrete Creep and Shrinkage," Report No. 82-4/665b, Center for Concrete and Geomaterials, Northwestern University, April 1983. 